\title{
Typical Correlation Score between Economic Development Speed and Employment Rate
}

\author{
Lixin Cui, Qian Hu, Lei Wang, Xinqian Wu \\ School of Mathematics and Statistics, Henan University of Science and Technology, Luoyang, China \\ Email: 1015485700@qq.com
}

How to cite this paper: Cui, L. X., Hu, Q., Wang, L., \& Wu, X. Q. (2020). Typical Correlation Score between Economic Development Speed and Employment Rate. Open Journal of Social Sciences, 8, 221-228. https://doi.org/10.4236/jss.2020.89016

Received: August 6, 2020

Accepted: September 21, 2020

Published: September 24, 2020

Copyright $\odot 2020$ by author(s) and Scientific Research Publishing Inc. This work is licensed under the Creative Commons Attribution International License (CC BY 4.0).

http://creativecommons.org/licenses/by/4.0/

\begin{abstract}
In order to discuss the relationship between the employment rate and the economic development speed, the typical correlation analysis between the development speed and the employment rate is made in the past 20 years. Three indicators of development speed are considered: per capita energy consumption, per capita GDP, fixed asset investment price index, and two indicators of employment rate are considered: number of graduates and number of employees. The results show that economic development has a great impact on the number of employment, and that economic development can increase the quantity of employment.
\end{abstract}

\section{Keywords}

Economic Development Speed, Employment Rate, Typical Correlation

\section{Introduction}

With the rapid development of society, the economy is in the process of normalization from high-speed growth to high-quality growth, and the employment situation and employment rate have also attracted people's attention. Whether a society's employment problem is solved well or not involves all aspects of society, and its influence is extremely extensive and far-reaching. Therefore, the relationship between employment rate and economic change is a topic worthy of discussion.

The speed of economic development refers to the relative number reflecting the degree of change of economic and social phenomena in time, which is an important indicator to measure the economic operation. The rate of employment and the speed of economic development are more worthy of discussion. Many scholars at home and abroad have also discussed this issue.

In order to understand the internal relationship between the employment rate 
and the economic development speed objectively, we select the relevant indicators of the economic development speed and the employment rate, and make a typical correlation analysis based on the data of 2000-2018.

\section{Literature Review}

Wang et al. (2017) obtained that there is a long-term equilibrium relationship between economic growth and employment in Xinjiang based on the data from 1992-2014. Lin (2016) explored the role of labor employment in promoting economic development in China. Liu et al. (2016) analyzed the evolution characteristics of China's economic growth and employment quality index system. Chen et al. (2019) analyzed the changes in the employment situation of college graduates in China under the new normal of current economic development, studied the difficulties and incentives faced by college graduates in employment, and put forward the corresponding strategies in an exploratory way. Luo \& Liu (2017) analyzed the current general employment situation of college graduates and the general economic trends at home and abroad, analyzed the main problems faced by college graduates in employment, and put forward corresponding countermeasures.

Chen \& Rong (2019) based on the time series of women's employment in Northeast China from 2000 to 2016, used VAR model and cointegration test to examine the relationship between women's employment and economic growth, and used employment elasticity coefficient to analyze the relationship between women's employment and economic growth in Northeast China, and discussed the choice of women's employment industry in Northeast China. Yu (2017) analyzed the existing problems and some restrictive factors in the employment process of college students, such as national policies, social and economic development, professional structure of schools, curriculum setting, college students' personal orientation and employment attitude. Byerlee and Eicher (1974) pointed out that the problem of urban unemployment is becoming more and more serious and many economists changed the main development index to redefining development. Tsaliki (2009) discussed the dynamics of economic development and its impact on employment, indicating that high unemployment may also be consistent with normal capital employment. John Nkwoma Inekwe (2013) investigated the relationship between employment and foreign direct investment in manufacturing and service industries in Nigeria.

\section{Canonical Correlation Analysis}

Canonical correlation analysis is a multivariate statistical method to study the correlation between two groups of variables. According to the correlation between variables, we find a few pairs of comprehensive variables (linear combination of actual observation variables) and use them to replace the original observation variables, so as to focus the relationship between two groups of variables on a few pairs of comprehensive variables. 
Let $X=\left(X_{1}, X_{2}, \cdots, X_{p}\right)^{\prime}, Y=\left(Y_{1}, Y_{2}, \cdots, Y_{q}\right)^{\prime}$ are two random vectors. Using the principal component theory, we find the $i$-th pair of typical related variables $\left(\begin{array}{ll}U_{i}, V_{i}\end{array}\right)$, where $U_{i}=a_{i 1} X_{1}+a_{i 2} X_{2}+\cdots+a_{i p} X_{p}=a_{i}^{\prime} X$, $V_{i}=b_{i 1} Y_{1}+b_{i 2} Y_{2}+\cdots+b_{i p} Y_{p}=b_{i}^{\prime} Y, i=1,2, \ldots, m=\min (p, q)$; the canonical correlation coefficient between the $m$-th pair of canonical correlation variables is $\operatorname{Can} R_{m}=\operatorname{Corr}\left(U_{m}, V_{m}\right)$.

In this paper, the typical correlation analysis of energy consumption per capita, GDP per capita, fixed asset investment price index with the number of graduates and employment is carried out. For convenience, let $x_{1}$ be the per capita energy consumption, $x_{2}$ be the per capita GDP, $x_{3}$ be the fixed asset investment price index, $y_{1}$ be the number of graduates, $y_{2}$ be the number of employees (Table 1).

\subsection{Typical Correlation Coefficient and Significance Test}

Two typical correlation coefficients are given in Table 2, the first one is Can $R_{1}=$

Table 1. Employment rate and development rate indicator.

\begin{tabular}{|c|c|c|c|c|c|}
\hline $\begin{array}{c}\text { Particular } \\
\text { year }\end{array}$ & $\begin{array}{c}\text { Annual per } \\
\text { capita energy } \\
\text { consumption (kg } \\
\text { standard coal) } x_{1}\end{array}$ & $\begin{array}{c}\text { GDP per } \\
\text { capita (yuan) } \\
x_{2}\end{array}$ & $\begin{array}{l}\text { Fixed asset } \\
\text { investment } \\
\text { price index } \\
\qquad x_{3}\end{array}$ & $\begin{array}{c}\text { Graduation } \\
\text { number }(10,000 \\
\text { people) } y_{1}\end{array}$ & $\begin{array}{c}\text { Number of } \\
\text { Employed Persons } \\
(10,000 \text { people }) y_{2}\end{array}$ \\
\hline 2000 & 132 & 7942 & 101.1 & 88,910 & 72,058 \\
\hline 2001 & 136 & 8717 & 100.4 & 89,849 & 72,797 \\
\hline 2002 & 146 & 9506 & 100.2 & 90,302 & 73,280 \\
\hline 2003 & 166 & 10,666 & 102.2 & 90,976 & 73,736 \\
\hline 2004 & 191 & 12,487 & 105.6 & 92,184 & 74,264 \\
\hline 2005 & 211 & 14,368 & 101.6 & 94,197 & 74,647 \\
\hline 2006 & 230 & 16,738 & 101.5 & 95,068 & 74,378 \\
\hline 2007 & 250 & 20,494 & 103.9 & 95,833 & 75,321 \\
\hline 2008 & 254 & 24,100 & 108.9 & 96,680 & 75,564 \\
\hline 2009 & 264 & 26,180 & 97.6 & 97,484 & 75,828 \\
\hline 2010 & 273 & 30,808 & 103.6 & 99,938 & 76,105 \\
\hline 2011 & 294 & 36,302 & 106.6 & 100,283 & 76,420 \\
\hline 2012 & 313 & 39,874 & 101.1 & 100,403 & 76,704 \\
\hline 2013 & 335 & 43,684 & 100.3 & 100,582 & 76,977 \\
\hline 2014 & 346.1 & 47,005 & 100.5 & 100,469 & 77,253 \\
\hline 2015 & 365.4 & 50,028 & 98.2 & 100,361 & 77,451 \\
\hline 2016 & 393.2 & 53,680 & 99.4 & 100,260 & 77,603 \\
\hline 2017 & 415.6 & 59,201 & 105.8 & 99,829 & 77,640 \\
\hline 2018 & 439.9 & 64,644 & 105.4 & 99,357 & 77,856 \\
\hline
\end{tabular}

Data source: The National Bureau of Statistics. 
Table 2. Canonical correlation analysis.

\begin{tabular}{ccccc}
\hline & $\begin{array}{c}\text { Canonical } \\
\text { Correlation }\end{array}$ & $\begin{array}{c}\text { Adjusted Canonical } \\
\text { Correlation }\end{array}$ & $\begin{array}{c}\text { Approximate } \\
\text { Standard Error }\end{array}$ & $\begin{array}{c}\text { Squared } \\
\text { Canonical Correlation }\end{array}$ \\
\hline 1 & 0.979105 & 0.976708 & 0.009747 & 0.958647 \\
2 & 0.146047 & -0.035772 & 0.230675 & 0.021330 \\
\hline
\end{tabular}

0.979105 , the correction value is 0.976708 , the standard error is 0.009747 , Can $R_{12}$ $=0.958647$, the first typical correlation coefficient shows that the correlation between the first pair of typical correlation variables is high.

Table 3 shows the characteristic roots and the corresponding statistics. It can be seen that $99.9 \%$ of the total variation can be explained by the first pair of typical variables, and the second pair has little effect on the typical related variables, only $0.1 \%$ of the total variation can be explained, which can be ignored.

Table 4 shows the test of typical correlation coefficient. The results show that the $\mathrm{F}$ value of the first row is 18.53 , $p$-value $<0.0001$. Under the test level of 0.05 , the original hypothesis is rejected, and the first correlation coefficient is not 0 ; the $p$-value of the second row is 0.8507 , far greater than the significance level of 0.05 , so only the first typical correlation coefficient is not 0 .

Table 5 shows the results of F-test with all typical correlation coefficients of 0 by four multivariate statistical methods. The test results of the four methods in this case are completely consistent with the above, indicating that at least one typical correlation coefficient is not 0 at the significant level of 0.05 .

\subsection{Typical Variable Coefficient and Typical Structure}

Because the units of the five indexes are not uniform, the standardized coefficient is considered. Table 6 and Table 7 show the typical variable coefficients expressed by standardized variables, and the relevant expressions of VAR variables (economic development speed) and WITH variables (employment rate) can be obtained as follows

$$
\begin{gathered}
V_{1}=1.3265 x_{1}^{*}-0.3316 x_{2}^{*}-0.0111 x_{3}^{*} \\
W_{1}=-0.3971 y_{1}^{*}+1.3742 y_{2}^{*}
\end{gathered}
$$

Among them, $V_{1}$ is the first typical variable of economic development speed, $W_{1}$ is the first typical variable of employment rate.

Formula (1) is the weighted difference between the per capita energy consumption and the per capita GDP approximately, with a greater weight in the per capita energy consumption and a coefficient of 0 in the fixed asset investment price index; Formula (2) shows that the first typical variable of employment rate, $W_{1}$, has the largest coefficient in the number of employed people.

Table 8 and Table 9 are the analysis results of the correlation between the original standardized variables and the typical variables of the matching group. The first typical variable $W_{1}$ of per capita energy consumption and per capita GDP and employment rate index has a strong correlation, indicating that the 
Table 3. Characteristic roots and corresponding statistics.

\begin{tabular}{cccccc}
\hline & Eigenvalue & Difference & Proportion & Cumulative & Likelihood Ratio \\
\hline 1 & 23.18 & 23.16 & 0.999 & 0.999 & 0.040471 \\
2 & 0.021 & & 0.000 & 1.000 & 0.978670 \\
\hline
\end{tabular}

Table 4. Test of the canonical correlations.

\begin{tabular}{ccccc}
\hline & Approximate F Value & Num DF & Den DF & $\operatorname{Pr}>$ F \\
\hline 1 & 18.53 & 6 & 28 & $<0.0001$ \\
2 & 0.16 & 2 & 15 & 0.8507 \\
\hline
\end{tabular}

Table 5. Multivariate statistics and F approximations.

\begin{tabular}{cccccc}
\hline Statistic & Value & F Value & Num DF & Den DF & Pr $>$ F \\
\hline Wilks' Lambda & 0.04047106 & 18.53 & 6 & 28 & $<0.0001$ \\
Pillai's Trace & 0.97997675 & 4.80 & 6 & 30 & 0.0015 \\
Hotelling-Lawley Trace & 23.2037669 & 52.60 & 6 & 17 & $<0.0001$ \\
Roy's Greatest Root & 23.18197214 & 115.91 & 3 & 15 & $<0.0001$ \\
\hline
\end{tabular}

Table 6. Canonical correlation analysis-standardized canonical coefficients for the VAR variables.

\begin{tabular}{ccc}
\hline & $V_{1}$ & $V_{2}$ \\
\hline$x_{1}^{*}$ & 1.3265 & -5.5679 \\
$x_{2}^{*}$ & -0.3316 & 5.6455 \\
$x_{3}^{*}$ & -0.0111 & 0.5728 \\
\hline
\end{tabular}

Table 7. Canonical correlation analysis-standardized canonical coefficients for the WITH variables.

\begin{tabular}{ccc}
\hline & $W_{1}$ & $W_{2}$ \\
\hline$y_{1}^{*}$ & -0.3971 & -3.4891 \\
$y_{2}^{*}$ & 1.3742 & 3.2316 \\
\hline
\end{tabular}

Table 8. Correlations between the VAR variables and the canonical variables of the WITH variables.

\begin{tabular}{rll}
\hline & $W_{1}$ & $W_{2}$ \\
\hline$x_{1}^{*}$ & 0.9777 & 0.0073 \\
$x_{2}^{*}$ & 0.9552 & 0.0274 \\
$x_{3}^{*}$ & 0.0890 & 0.0557 \\
\hline
\end{tabular}

faster the economic development is, the higher the employment rate is; the number of graduates and number of employees are positively correlated with the first typical variable $V_{1}$ of development rate. It shows that the development 
speed has a positive role in promoting the employment rate.

\subsection{Typical Redundancy Analysis}

Table 10 is the proportion of variance explained by the normalized variance of the rate of economic development through its typical variables and paired typical variables. It can be seen that the proportion of shared variance explained by the index of economic development through its first typical variable is $65.23 \%$, and the proportion of variance explained by the other's first typical variable is $62.54 \%$, and its ratio 62.54/65.23 $=0.9586$ is exactly $\operatorname{Can} R_{1}^{2}$.

Table 11 is the proportion of variance explained by the standardized variance of the employment rate variable through its canonical and paired canonical variables. It can be seen that the proportion of the shared variance explained by the employment rate index through the first canonical variable is $91.70 \%$, which is accounted for. The proportion of variance explained by the typical variable is $87.91 \%$, and the ratio is also 0.9586 .

Table 12 and Table 13 give the squares of the complex correlation coefficients between the original variables and the typical variables of the paired group, that

Table 9. Correlations between the WITH variables and the canonical variables of the VAR variables.

\begin{tabular}{ccc}
\hline & $V_{1}$ & $V_{2}$ \\
\hline$y_{1}^{*}$ & 0.9010 & -0.0572 \\
$y_{2}^{*}$ & 0.9728 & -0.0165 \\
\hline
\end{tabular}

Table 10. Standardized variance of the VAR variables explained by their own canonical and the opposite canonical variables.

\begin{tabular}{cccccc}
\hline \multicolumn{5}{c}{ Standardized Variance of the VAR Variables Explained by } \\
\hline \multicolumn{5}{c}{ Their Own Canonical Variables } & \multicolumn{2}{c}{ The Opposite Canonical Variables } \\
\hline Variable & & Cumulative & Canonical & & Cumulative \\
Number & Proportion & Proportion & R-Square & Proportion & Proportion \\
\hline 1 & 0.6523 & 0.6523 & 0.9586 & 0.6254 & 0.6254 \\
2 & 0.0611 & 0.7134 & 0.0213 & 0.0013 & 0.6267 \\
\hline
\end{tabular}

Table 11. Standardized variance of the WITH Explained by their own canonical variables and the opposite canonical variables.

\begin{tabular}{cccccc}
\hline \multicolumn{5}{c}{ Standardized Variance of the WITH Variables Explained by } \\
\hline \multicolumn{5}{c}{ Their Own Canonical Variables } & The Opposite Canonical Variables \\
\hline Variable & Cumulative & Canonical & Cumulative \\
Number & Proportion & Proportion & R-Square & Proportion & Proportion \\
\hline 1 & 0.9170 & 0.9170 & 0.9586 & 0.8791 & 0.8791 \\
2 & 0.0830 & 1.0000 & 0.0213 & 0.0018 & 0.8809 \\
\hline
\end{tabular}


Table 12. Squared multiple correlations between the VAR variables and the first $M$ canonical variables of the WITH variables.

\begin{tabular}{ccc}
\hline$M$ & 1 & 2 \\
\hline 0.9558 & 0.9559 \\
0.9124 & 0.9131 \\
0.0079 & 0.0110 \\
\hline
\end{tabular}

Table 13. Squared multiple correlations between the WITH variables and the first $M$ canonical variables of the VAR variables.

\begin{tabular}{ccc}
\hline$M$ & 1 & 2 \\
\hline & 0.8118 & 0.8151 \\
& 0.9464 & 0.9467 \\
\hline
\end{tabular}

is, the determination coefficients of the original variables and the typical variables. It can be seen that the first typical variable of the index of economic development has a fairly good explanatory power for the number of graduates $\left(y_{1}\right)$ and the number of employed people $\left(y_{2}\right)$. The first typical variable of the employment rate indicator has a fairly good explanatory power for per capita energy living consumption $\left(x_{1}\right)$ and per capita GDP $\left(x_{2}\right)$, while it has little explanatory power for the fixed asset investment price index $\left(x_{3}\right)$.

To sum up, $W_{1}$, the first typical variable of economic development speed index, has quite good explanatory power to the number of graduates and the number of employed people. $V_{1}$, the first typical variable of employment rate index, has a good explanatory power to per capita energy consumption and per capita GDP, but has little explanatory power to fixed asset investment price index. The first typical variable of the speed index of economic development has the strongest ability to explain the number of employed people in the employment rate index, which shows that economic development has a great influence on the number of employed people, and at the same time, accelerating economic development can increase the number of employed people.

\section{Conclusion}

We mainly discuss a typical correlation analysis on the development speed and employment rate. The research results show that the first typical variable of the economic development speed index has the strongest ability to explain the employment index in the employment rate index, that is, economic development has a greater impact on employment, and accelerating economic development can increase employment.

The research on the promotion of college students' employment under the new economic situation is helpful for people to objectively understand the relationship between economic development and employment and its evolution trend, and has certain reference significance and application value for relevant 
departments to make scientific decisions and formulate policies and measures. The quantitative research method of this topic enriches the research ideas of the relationship between economic development and employment, and broadens the methods for further study of this problem.

\section{Conflicts of Interest}

The authors declare no conflicts of interest regarding the publication of this paper.

\section{References}

Byerlee D. R., \& Eicher, C. K. (1974). Rural Employment, Migration, and Economic Development: Theoretical Issues and Empirical Evidence from Africa. In N. Islam, Ed., Agricultural Policy in Developing Countries (pp. 73-313), Bad Godesberg, West Germany. https://doi.org/10.1007/978-1-349-63663-1_11

Chen, T. M., Wang, H. H., \& Tian, Y. (2019). On the Employment Situation of College Students under the New Normal of Economic Development. China Business Theory, No. 16, 247-248.

Chen, Y. Z., \& Rong, J. (2019). Research on Female Employment and Economic Growth in Northeast China. Economic Issues, No. 2, 94-100.

Inekwe, J. N. (2013). FDI, Employment and Economic Growth in Nigeria. African Development Review, 25, 421-433. https://doi.org/10.1111/1467-8268.12039

Lin, L. Y. (2016). The Role of China's Labor Employment in Promoting Economic Development. New Economy, No. 15, 33.

Liu, J., Guo, S. Q., \& Jin, C. Y. (2016). Research on the Coupling of Economic Growth, Economic Structure, and Employment Quality: Empirical Evidence Based on Macro Data from 2005 to 2014. Macroeconomic Research, No. 5, 99-105.

Luo, J. H., \& Liu, H. Y. (2017). Exploring the Relationship between College Students' Employment and Economic Development. Finance and Economics, No. 10, 55-56.

Tsaliki, P. V. (2009). Economic Development and Unemployment: Do They Connect? In ternational Journal of Social Economics, 36, 773-781. https://doi.org/10.1108/03068290910963707

Wang, T. X., Wang, Z. Z., \& Wang, T. (2017). Economic Growth, Industrial Develop ment, and Labor Employment in Xinjiang: Empirical Evidence from 1992-2014. Xinjiang Agricultural Reclamation Economy, No. 2, 29-34

Yu, F. Q. (2017). On the Impact of Current Social System and Economic Development on College Students’ Employment. Economic Research Guide, No. 5, 42-43+56. 